\title{
Desafios e possibilidades da formação docente em pesquisas com intervenção no mestrado profissional
}

\section{Challenges and possibilities of teacher's formation in researches under intervention within the professional master}

\author{
Marlene Zwierewicz ${ }^{1}$ \\ Alessandra Garcia Zanol ${ }^{2}$ \\ Marli Horn ${ }^{3}$
}

\section{Resumo}

Este ano de 2020 representa um desafio evidencia a emergência de mudanças paradigmáticas nos diferentes segmentos da sociedade. Considerando que os sistemas educacionais se veem profundamente afetados pela pandemia provocada pelo coronavírus SARS-CoV-2, este artigo tem como situação mobilizadora a necessidade de transformações na prática pedagógica. Seu objetivo é apresentar duas propostas formativas vinculadas a pesquisas do Programa de PósGraduação Mestrado Profissional em Educação Básica da Universidade Alto Vale do Rio do Peixe. $\mathrm{Na}$ primeira, pretende-se apresentar como produto educacional uma proposta estruturada com base no que já vem sendo realizado no Programa de Formação-Ação em Escolas Criativas, mas adaptado à realidade de docentes de outra escola, bem como aos Objetivos de Desenvolvimento Sustentável (ODS); na segunda, o produto pretende ser constituído pela proposta original aplicada, com adaptação à realidade de outro grupo de docentes. A primeira caracteriza-se como uma pesquisa participante e a segunda como uma pesquisa-ação, ambas priorizam a abordagem qualitativa. No texto são consideradas contribuições de autores como Gatti (2014, 2017), Imbernón (2016), Nicolescu (2014) e Nóvoa (2017). Por estarem as pesquisas em processo, seus resultados ainda não são passíveis de apresentação. A versão preliminar do produto derivado da primeira pesquisa denota a interdependência entre a formação e os contextos local e global; já a intervenção da segunda pesquisa indica que os docentes que participam dos encontros formativos têm buscado implementar nas escolas em que atuam iniciativas comprometidas com a transformação da prática pedagógica, elaboradas colaborativamente durante a própria formação.

Palavras-chave: Formação docente; transdisciplinaridade; ecoformação.

\footnotetext{
${ }^{1}$ Doutora em Psicologia e Doutora em Educação, Coordenadora do Programa de Pós-Graduação Mestrado Profissional em Educação Básica (PPGEB) da Universidade Alto Vale do Rio do Peixe (UNIARP), Caçador, Santa Catarina, Brasil). ORCID: https://orcid.org/0000-0002-5840-1136. Contato: marlenezwie@yahoo.com.

${ }^{2}$ Mestranda do Programa de Pós-Graduação Mestrado Profissional em Educação Básica (PPGEB). ORCID: https://orcid.org/0000-0002-5102-557X. Contato: aleszanol@yahoo.com.br.

${ }^{3}$ Mestranda do Programa de Pós-Graduação Mestrado Profissional em Educação Básica (PPGEB). ORCID: https://orcid.org/0000-0002-0737-8749. Contato: hornmarly@hotmail.com.
} 


\begin{abstract}
This year of 2020 has been a challenge to humanity, and it highlights the emergency of paradigmatic changes in different segments of society. Considering that the educational systems are profoundly affected by the pandemics caused by the coronavirus SARS-CoV-2, this article has as its mobilizer situation the necessity of transformations in the pedagogical practices. Its aim is to present two formative proposals bound to the researchers of the Post graduation Program of Professional Master in Elementary Education of the University of Alto Vale do Rio do Peixe: in the first one a structured proposal based on that which has been done in the Formation-Action Program in Creative Schools is presented as educational product, however it is adapted to the reality of teachers from a school, as well as to the Sustainable Development Objectives (SDO); in the second one the product is made by the applied original proposal, but with some adaptation to the reality of teachers from other school. The first is characterized by a participant research, the second implies an action-research, both prioritized the qualitative approach. In the text, authors such as Gatti (2014, 2017), Imbernón (2016), Nicolescu (2014), Nóvoa (2017) are considered. The first research shows the interdependence between the formation and the global and local context; while the second research counts on the teachers' participation who have tried to implement, within the schools where they work, initiatives that are compromised with the transformation of the pedagogical practices and these practices are elaborated collaboratively during their own formation.
\end{abstract}

Keywords: Teacher formation; transdisciplinarity; ecoformation.

\title{
Introdução
}

Uma educação articulada à realidade vincula conhecimentos curriculares às emergências de cada momento da história e, quando possível, deve se antecipar a elas, projetando possíveis soluções amparadas no conhecimento sobre o passado, na compreensão da complexidade presente e na atenção às incertezas sobre o futuro. Especialmente neste ano, em que a pandemia causada pelo coronavírus SARS-CoV-2 “[...] tem se apresentado como um dos maiores desafios sanitários em escala global deste século [...]" (WERNECK; CARVALHO, 2020, p. 1), observa-se a emergência de mudanças profundas em áreas como a saúde, economia e educação.

No campo educacional, especificamente, a condição atual e as incertezas diante do futuro requisitam dos docentes novas formas de trabalhar os processos de ensino e de aprendizagem, demandando o trânsito para novas possibilidades paradigmáticas. Ou seja, transitar para um paradigma educacional capaz de colaborar não apenas com o uso de uma vastidão de informações pelos estudantes - e que a cada dia se tornam mais acessíveis e se 
diversificam por meio de diferentes mídias -, mas que também favoreça práticas pedagógicas que os mobilizem a identificar problemas e a trabalhar colaborativamente na sua resolução, estimulando sua resiliência no enfrentamento de adversidades enquanto se apropriam dos conhecimentos curriculares.

Destaca-se, portanto, a necessidade de um paradigma que articule os conhecimentos desenvolvidos até então de modo atomizado, para que essa interconexão possibilite uma compreensão mais profunda da realidade. Essa condição pode ser vivenciada por docentes em ambientes que lhes possibilitem “[...] transformar sua realidade e transformar-se [...]" (REBOLO; BUENO, 2014, p. 324).

Para tanto, é indispensável investir em uma formação docente que, de acordo com Gatti (2017, p. 722), considere as condições situacionais, tendo clareza das suas finalidades, ou seja, “[...] os porquês, o para quê e o para quem é realizada essa formação, assumindo compromissos éticos e sociais". Este artigo, pautado nessa perspectiva, tem como objetivo apresentar duas propostas formativas vinculadas a pesquisas do Programa de Pós-Graduação Mestrado Profissional em Educação Básica (PPGEB) da Universidade Alto Vale do Rio do Peixe (UNIARP), de Caçador, Santa Catarina.

A primeira proposta faz parte de uma pesquisa participante e a segunda de uma pesquisa-ação, ambas priorizam a abordagem qualitativa e têm como foco docentes da Educação Básica. A primeira pretende atender necessidades formativas de profissionais que atuam na mesma escola da pesquisadora, enquanto a segunda envolve, além de profissionais do lócus de atuação da pesquisadora, docentes de outras instituições da Rede Municipal de Ensino.

Essas iniciativas coadunam com a necessidade de a formação dinamizar alternativas que, de fato, ofereçam um suporte teórico-metodológico capaz de dialogar com as demandas dos campos de atuação profissional. Nesse sentido, priorizam a transição de propostas formativas descontextualizadas para perspectivas formativas transdisciplinares e ecoformadoras mobilizadas pelo pensamento complexo.

Sistematizadas a seguir, as iniciativas são precedidas por reflexões sobre mudanças necessárias à própria formação docente, situando-se, também, a relevância da pesquisa com intervenção para o PPGEB. Espera-se que o relato das iniciativas subsidie novas reflexões comprometidas com o atendimento de emergências de uma realidade em acelerada transformação. 


\section{Da formação docente descontextualizada a perspectivas transdisciplinares e ecoformadoras}

A formação docente inicial e continuada tem se destacado entre os debates da área educacional. Isso se justifica pela importância de formar profissionais cada vez mais capazes de lidar com as demandas da realidade atual e com as incertezas em relação ao futuro. Apesar dessas preocupações, Gatti (2014, p. 36) relata que "Há um acúmulo de impasses e problemas historicamente construídos [...] na formação de professores em nível superior no Brasil que precisa ser enfrentado [...]", pois, conforme a autora, formar docentes é muito diferente de formar especialistas disciplinares.

Assim, essa problemática inclui não apenas os docentes da Educação Básica, mas também os do Ensino Superior. Imbernón (2016) é um dos autores que destaca o aumento da preocupação com a formação de docentes universitários e as implicações dessa perspectiva nas políticas institucionais, nas pesquisas e nas publicações. Em sua análise, o autor faz referência ao momento de transição vivenciado atualmente, destacando a persistência de programas de formação baseados no modelo tradicional, mas também o surgimento de reflexões que podem contribuir para mudanças no cenário formativo.

Em relação à formação inicial, Gatti (2014) destaca a incipiência no contexto brasileiro de propostas capazes de adequar o currículo às necessidades atuais de ensino, no sentido de ser revista a estrutura da formação ofertada pelas licenciaturas. Em contrapartida, defende que os cursos de licenciatura propiciem experiências que envolvam, entre outros aspectos, valores individuais e coletivos para melhorar a formação.

Ao discutir o paradigma de formação docente que prioriza a descontextualização, Behrens (2007, p. 441) afirma que "A abordagem enciclopédica na docência acompanhou os professores por muitos séculos e carregou como maior herança o distanciamento entre teoria e prática e a reprodução do conhecimento". Gatti et al. (2019, p. 16), por sua vez, reforçam que “[...] a situação social que vivenciamos contemporaneamente não pode ser deixada de lado quando se pensa a educação das novas gerações: seus movimentos, diferenciações, conflitos, realizações, contradições, renovações/ inovações”. Portanto, “[...] as dinâmicas curriculares na 
formação de professores [...] precisam reinventar-se. Para isso é necessário ter consciência de que a formação oferecida não é suficiente ou adequada [...]” (GATTI, 2017, p. 733).

Nóvoa (1992, p. 14) corrobora com essa visão ao afirmar que: “É preciso trabalhar no sentido da diversificação dos modelos e das práticas de formação, instituindo novas relações dos professores com o saber pedagógico e científico”. O autor também alerta que:

[...] nos últimos anos, tem vindo a crescer um sentimento de insatisfação, que resulta da existência de uma distância profunda entre as nossas ambições teóricas e a realidade concreta das escolas e dos professores, como se houvesse um fosso intransponível entre a universidade e as escolas, como se a nossa elaboração acadêmica pouco tivesse contribuído para transformar a condição socioprofissional dos professores (NÓVOA, 2017, p. 1108-1109).

Entre as alternativas, Imbernón (2016) defende que, em vez de partir de especialistas, a formação continuada deveria contar com a reflexão dos docentes sobre sua própria prática. Portanto, além de ser necessário discutir e modificar o referencial da formação ofertada nos cursos de licenciatura, é emergencial haver uma reflexão acerca da formação continuada, para que sejam identificadas alternativas que considerem a complexidade dos campos de atuação docente. Essa condição depende do potencial transdisciplinar e ecoformador dessas reflexões.

Torre (2008, p. 34-35) justifica a ênfase nessas perspectivas quando afirma que "Educar implica, a partir de um olhar transdisciplinar e ecoformador, valorizar, reconhecer, respeitar e outorgar confiança e credibilidade aos outros". Ou seja, mais do que atualizar e ensinar, a formação precisa colaborar para a criação de condições, de planejamento e de ambientes em que os docentes possam aprender (IMBERNÓN, 2016) de forma colaborativa e conectada com o contexto local e global.

Nesse sentido, Gatti (2014, p. 378) defende que “[...] são necessárias ações conscientes, baseadas em uma reflexão mais objetiva sobre a realidade experimentada, vivenciada [...]". São opções com esse foco que, para a autora, impulsionam "[...] atitudes e ações inovadoras, que se traduzam em práticas efetivas de mudança”. Para tanto, Imbernón (2016, p. 140) sugere uma análise profunda das políticas formativas para que essas não se limitem à oferta de cursos, em sua maioria, de curta duração, pois "[...] a formação não deve se limitar a um acúmulo de cursos nem ser planejada como um remédio capaz de resolver todos os nossos males".

Revista Devir Educação, Lavras, vol.2, n.4, p.232-250 jul./dez., 2020. 
Para a transição das formações descontextualizadas às perspectivas da transdisciplinaridade e da ecoformação, há a necessidade de lembrar que a agenda educativa para os próximos anos terá de estar direcionada não apenas aos processos de construção do conhecimento e da aprendizagem, mas também às questões da sustentabilidade ecológica. É com essa perspectiva que pode ser estimulada uma cidadania planetária vinculada à consciência humana em uma perspectiva integradora (TORRE, 2008).

Para tanto, Moraes (2010, p. 178) lembra que "[...] é preciso um esforço coordenado, sistemático e simultâneo que articule vários aspectos [...]”. Entre eles, a autora destaca a possibilidade de se criar um diálogo mais efetivo entre o Estado, a sociedade e as organizações docentes, para que, de uma forma global, sejam repensados os programas, os projetos e as estratégias de formação, além de serem priorizados "[...] novos referenciais teóricos relacionados aos novos paradigmas da ciência”.

Torre (2008, p. 37) corrobora com essas afirmações quando afirma que práticas transdisciplinares e ecoformadoras fortalecem-se por políticas sociais, institucionais, empresariais e trabalhistas baseadas “[...] no respeito, na convivência, na conservação dos meios naturais, na melhoria das condições de vida, no consumo razoável e em uma produtividade que não menospreze os direitos humanos". Contudo, é preciso reconhecer que essa não é uma transição fácil, "[...] pois se trata de uma mudança na cultura profissional, que comporta um processo complexo" (IMBERNÓN, 2016 p. 144). Para o autor, essas mudanças podem exigir um tempo expressivo, pois fazem parte de um processo não linear constituído por fatores como a realidade escolar, o contexto, as etapas e os níveis de ensino.

Tais apontamentos levam à reflexão sobre as possibilidades docentes, incluindo as condições de trabalho e a disponibilidade para mudanças tão necessárias ao desenvolvimento de práticas educativas emergenciais. Entretanto, a pandemia não possibilitou um tempo amplo para essas mudanças, requisitando a emergência em formações que auxiliem os docentes a "[...] superar conceitos arraigados e hábitos perpetuados secularmente [...]" a fim de que possam “[...] ter condições de inovar" (GATTI, 2014, p. 36).

Torre (2008) salienta que toda reforma educativa deve ter, aproximadamente, $60 \%$ de utopia e que o melhor dessa iniciativa não se constitui somente pelos resultados, mas pelas ideias e pelos aspectos inovadores que funcionam como motor de troca para uma atualização permanente. Sobre essa perspectiva, Moraes (2010) enfatiza a relevância de serem desenvolvidas experiências que estimulem os profissionais a refletirem criticamente sobre 
suas práticas, a fim de organizarem ambientes agradáveis, prazerosos, acolhedores e efetivos de aprendizagem.

Gatti (2014, p. 378), por sua vez, defende que "O desenvolvimento profissional alia-se a se ter uma visão mais clara do que impede movimentos de transformação de si ou de uma realidade, no caso de nossa realidade educacional próxima, nas escolas, e nas redes educacionais, no ensino e em sua gestão". Nesse sentido “[...] uma competência básica na formação de professores é a capacidade de entender a vida a partir de uma visão criativa e ativa [...]" (TORRE, 2008, p. 45), demandando

[...] ações conscientes, baseadas em uma reflexão mais objetiva sobre a realidade experimentada, vivenciada; reflexão que impulsionará atitudes e ações inovadoras, que se traduzam em práticas efetivas de mudança. Isso só se efetivará com um esforço de superação de nossa condição de rotina na vida cotidiana, na busca constante de entender com clareza as situações em que vivemos e trabalhamos, para mudarmos, avançarmos em relação à situação atual (GATTI, 2014, p. 378).

Essa é a perspectiva do PPGEB quando investe em pesquisas com intervenção que envolvem a formação docente. São exemplos as desenvolvidas pelas egressas Almeida (2018) e Zielinski (2019) e, atualmente, as da segunda e da terceira autoras deste artigo.

Essas iniciativas buscam se aproximar das condições apresentadas por Nóvoa (1992, p. 17) ao afirmar que "A formação não se faz antes da mudança, faz-se durante, produz-se nesse esforço de inovação e de procura dos melhores percursos para a transformação da escola", ou seja, "[...] Só existe saber na invenção, na reinvenção, na busca inquieta, impaciente, permanente, que os homens fazem do mundo, com o mundo e com os outros" (FREIRE, 1975, p. 66).

\section{Os desafios da pesquisa com intervenção e o compromisso do PPGEB com a formação de docentes da Educação Básica}

$\mathrm{O}$ mestrado profissional surgiu em meio às necessidades de o país oferecer uma nova modalidade de ensino capaz de acompanhar as novas exigências sociais e de respondê-las. A Portaria $\mathrm{n}^{\circ}$ 47, de 17 de outubro de 1995, da Coordenação de Aperfeiçoamento de Pessoal de Nível Superior (CAPES), orientou as Instituições de Ensino Superior (IES) sobre a importância da criação de mestrados voltados à formação profissional, mas somente em 2009 
essa modalidade de ensino passou a ser efetivamente regulamentada, por meio da Portaria $\mathrm{n}^{\mathbf{o}}$ 7, do Ministério da Educação (MEC), com o objetivo oferecer soluções para os problemas provocados pelas céleres transformações sociais (PETARNELLA; SILVEIRA, 2015).

Os autores também destacam que os mestrados profissionais precisam lidar com o desafio de operar com mudanças no modo de a educação conceber pesquisas a partir da prática de intervenção. No caso específico dos mestrados profissionais em educação, essas pesquisas têm como especificidade o alcance de resultados práticos e precisam desenvolver potencialidades humanas focadas na possibilidade de resolução de problemas oriundos do cotidiano escolar.

“O que se propõe é que o profissional seja um pesquisador de sua prática e, para isso, a formação deve estar toda ela orientada para a pesquisa, de modo que o trabalho final de conclusão seja o resultado dessa pesquisa" (ANDRÉ; PRINCEPE, 2017, p. 105). As autoras afirmam que tal condição oportuniza que os profissionais da educação analisem a realidade em que se inserem, localizem áreas críticas que possam ser contextualizadas por meio de um processo sistemático de coleta de dados e de referenciais teórico-metodológicos para, assim, atuarem efetivamente nessa realidade. Essa perspectiva de pesquisa é articulada por meio de áreas de concentração, linhas e grupos de pesquisa, disciplinas e ementas de cada programa de mestrado (PETARNELLA; SILVEIRA, 2015).

No caso do PPGEB, o objetivo é promover a formação de gestores e docentes que investiguem e transformem as próprias ações e as instituições de ensino, visando seu aperfeiçoamento e a melhoria das práticas pedagógicas na Educação Básica (UNIARP, 2018). Para tanto, o programa vincula suas atividades a duas linhas de pesquisa: L1: Políticas Públicas e Gestão da Educação; L2: Cultura, Ensino, Saúde e Formação Docente. As pesquisas sistematizadas neste artigo estão vinculadas à L2, mas a pesquisa com intervenção vem sendo fortalecida em ambas as linhas.

Ao envolver a realidade de gestores e docentes, as linhas comprometem-se com pesquisas que contextualizam o campo de atuação e imprimem iniciativas para sua transformação, atendendo, dessa forma, a ênfase da modalidade profissional de mestrado defendida por autores como André e Princepe (2017) e Petarnella e Silveira (2015).

Para que a pesquisa com intervenção seja fortalecida, ampliou-se, especialmente a partir do ano de 2018, a articulação entre as disciplinas e destas com os contextos de atuação dos mestrandos e com demandas que geograficamente os extrapolam. Trata-se, portanto, de 


\section{OO DEVIR EDUCAÇÃO}

ISSN: 2526-849X

uma matriz curricular inter e transdisciplinar que se dinamiza por um movimento ecoformador, em função de o PPGEB centrar seus esforços em objetivos específicos que caracterizam esse viés, entre eles: estimular a formação de gestores e docentes comprometidos com o processo de transformação social, por meio da articulação entre o saber acadêmico, a pesquisa e a prática educativa; e estimular a pesquisa com intervenção na Educação Básica, para identificação, valorização, ressignificação e difusão de iniciativas de gestão e de ensino transdisciplinares e ecoformadoras (UNIARP, 2018).

Nesse processo, considera-se a perspectiva transdisciplinar, que Nicolescu (2014) situa como o que está entre as disciplinas, além e através delas. Da mesma forma, dinamiza-se um viés ecoformador, observado nas intervenções quando se viabiliza o que Silva (2008, p. 102) define como contato formador com as coisas, com os objetos e com a natureza e que se transforma em condição formadora "[...] de outras ligações, em especial das ligações humanas".

A matriz curricular do PPGEB aprofunda seu viés transdisciplinar e ecoformador quando articula o trabalho das disciplinas (ensino), os eventos que promove (extensão) e as iniciativas de intervenção (pesquisa), como se caracteriza na Figura 1. 


\section{PROGRAMA DE PÓS-GRADUAÇÃO \\ Uniarp MESTRADO PROFISSIONAL EM EDUCAÇÃO BÁSICA - PPGEB \\ MATRIZ CURRICULAR TRANSDISCIPLINAR E ECOFORMADORA

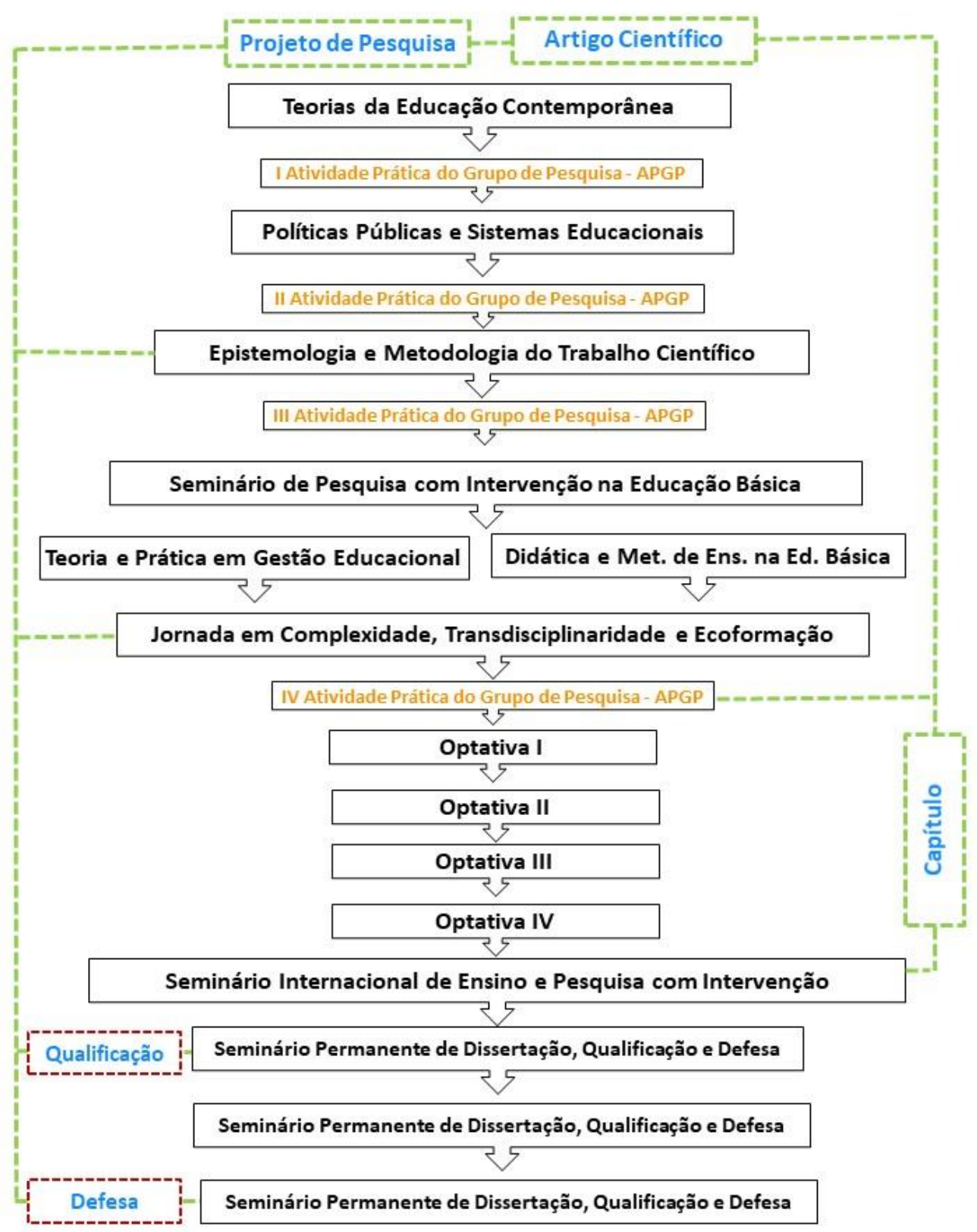

\section{GPECS \\ CET}

GIES

Figura 1: Matriz curricular do Programa de Pós-Graduação Mestrado Profissional em Educação Básica (PPGEB) Fonte: UNIARP (2018).

Revista Devir Educação, Lavras, vol.2, n.4, p.232-250 jul./dez., 2020. 
Essa forma de trabalhar a matriz curricular tem contribuído para que as pesquisas gerem impactos na transformação da prática pedagógica em escolas de Educação Básica. Parte desses impactos deriva de pesquisas com intervenção comprometidas com a formação docente nas instituições de ensino a que os próprios mestrandos se vinculam.

Essas pesquisas desafiam os mestrandos a se posicionarem como formadores de formadores ao se comprometerem em dinamizar, nos contextos de atuação, possiblidades discutidas e criadas no decorrer das disciplinas ou ao dar continuidade ao estudo de objetos de pesquisas de egressos. Como exemplo de pesquisas comprometidas com a formação docente e que utilizaram na intervenção projetos de ensino e de aprendizagem elaborados colaborativamente durante parte das disciplinas, destacam-se os estudos de Almeida (2018) e Zielinski (2019).

A primeira pesquisa teve como objetivo avaliar o potencial do Programa de FormaçãoAção em Escolas Criativas para transformar a prática pedagógica e atender as necessidades formativas de docentes de uma escola do campo vinculada à Rede Municipal de Ensino de Caçador, Santa Catarina. Com base em uma pesquisa-ação, apoiada na abordagem qualitativa, concluiu-se que a proposta formativa contribuiu para a transformação da prática pedagógica dos docentes, especialmente: a) na articulação teórico-prática, ao aproximar os conteúdos da realidade de inserção do estudantes, b) nas oportunidades para ampliar diálogos fundamentados na teoria, ressignificando a visão sobre os processos de ensino e de aprendizagem, c) na ampliação da criatividade e do protagonismo dos estudantes e d) no trabalho colaborativo. Em relação às necessidades formativas, a pesquisadora atendeu reivindicações relacionadas à formação, acentuando a discussão sobre o planejamento e a metodologia de ensino, estimulou a implicação dos pais e/ou responsáveis em várias ações desenvolvidas e fomentou o comprometimento dos estudantes e seu interesse pela apropriação dos conteúdos, especialmente por terem sido estes articulados com a realidade local, sem subestimar as exigências globais (ALMEIDA, 2017).

A segunda pesquisa teve como objetivo analisar as contribuições do Programa de Formação-Ação em Escolas Criativas para ressignificar as práticas pedagógicas de docentes de uma escola vinculada à Rede Municipal de Timbó Grande, em Santa Catarina. Em seu desenvolvimento, foram sistematizados indicadores de práticas transdisciplinares de leitura, produção e interpretação textual observados durante as atividades realizadas (ZIELINSKI, 
2019). Metodologicamente, o estudo também se caracterizou por uma pesquisa-ação, apoiada na abordagem qualitativa.

O fato de o projeto de ensino - planejado e aplicado pelos docentes durante a formação - envolver a realidade de Timbó Grande, Santa Catarina, resultou em possibilidades para que na prática pedagógica se valorizasse o diálogo com a realidade local na apropriação dos conceitos/conteúdos curriculares. Essa estratégia dinamizou práticas de leitura, interpretação e produção textual com uma efetiva relação entre texto e contexto. Além disso, as percepções dos docentes e dos estudantes possibilitaram que se identificassem dez indicadores de práticas transdisciplinares de leitura, produção e interpretação textual, são eles: vinculação das temáticas textuais à realidade local/global; suportes que articulam texto e contexto; utilização de cenários alternativos de aprendizagem; ampliação do conhecimento sobre a realidade próxima; articulação teórico-prática; valorização de conteúdos vivos; comprometimento com a transformação; estímulo à escuta e à observação; alternância nas interações; estímulo ao protagonismo (ZIELINSKI, 2019).

Defende-se que esse referencial de formação pode promover o desenvolvimento de “[...] um currículo em ação, um currículo vivo, flexível, aberto, sempre em processo de construção, o que garante o seu caráter dialógico [...]" diante de uma “[...] realidade mutante" (MORAES, 2011, p. 34-35). Para que essas ações se concretizem, Nóvoa (1992) reforça a importância de se criarem redes que possibilitem a troca de experiências e a partilha de saberes numa formação mútua, interativa e dinâmica, condição que é estimulada nas formações do PPGEB.

\section{Metodologia da pesquisa}

Entre os tipos de pesquisa, o PPGEB tem priorizado a pesquisa-ação e a participativa, sem desvalorizar outros referenciais que colaboram com a criação de produtos educacionais priorizados nos mestrados profissionais. No caso das duas experiências apresentadas adiante, a primeira constitui uma pesquisa participativa e a segunda uma pesquisa-ação, ambas priorizam a abordagem qualitativa.

Por estarem em andamento, neste artigo não será aprofundada a metodologia que as caracteriza. Ainda assim, destaca-se que as pesquisas implicam um número de participantes na coleta de dados e diferentes técnicas e instrumentos de pesquisa aplicados, tanto para 
levantar demandas formativas, como para avaliar a proximidade das formações (em forma de proposta ou de intervenção efetiva) das reais necessidades indicadas pelos participantes.

Os dados serão tratados com o Software MaxQDA, o que facilitará observar condições como a criação de nuvens de palavras a partir da frequência com que são utilizadas nas respostas. Além disso, ambas as pesquisas foram aprovadas pelo Comitê de Ética.

\section{Resultados e discussões}

A primeira pesquisa, desenvolvida por Alessandra Garcia Zanol, segunda autora deste artigo, objetiva elaborar uma proposta de formação transdisciplinar e ecoformadora compatível com as demandas de docentes que atuam nos anos finais do Ensino Fundamental de uma escola de Pato Branco, Paraná. Essa proposta também está comprometida com o proposto nos Objetivos de Desenvolvimento Sustentável (ODS) da Agenda 2030. Os objetivos específicos são: conhecer as demandas formativas dos docentes e suas sugestões para a elaboração da proposta formativa; analisar as etapas utilizadas no Programa de Formação-Ação em Escolas Criativas exploradas nas pesquisas de Almeida (2018) e Zielinski (2019), averiguando possibilidades de utilização na proposta formativa no lócus da pesquisa; avaliar, no decorrer da pesquisa, a aproximação da proposta formativa elaborada com as demandas formativas dos docentes do lócus da pesquisa; avaliar a aproximação da proposta formativa elaborada para o lócus da pesquisa com as premissas da transdisciplinaridade e da ecoformação, implícitas nos ODS.

Ao considerar condições locais e especificidades globais previstas nos ODS, o estudo converge com preocupações anunciadas por Morin (2011) quando o autor define o conhecimento pertinente como um dos saberes necessários para a educação do futuro (que agora já é presente). Ou seja, um conhecimento produzido por racionalidade aberta que contextualize e conceba a multidimensionalidade humana, social e da natureza (SÁ, 2019).

Por isso, a proposta tem como condições as possibilidades de promover, potencializar e valorizar, durante a formação, práticas pedagógicas criativas, pautadas no trabalho colaborativo, na solidariedade, no protagonismo e no exercício de um olhar antropoético e comprometido com necessidades e potencialidades locais e globais, sendo também atento às incertezas em relação ao futuro da humanidade. Trata-se de uma proposta ancorada nas experiências anteriores do Programa de Formação-Ação em Escolas Criativas 
(ZWIEREWICZ, 2017) e que, neste momento, abarca tanto demandas de docentes quanto um contexto específico com emergências globais. Essas duas condições diferenciam esta proposta da proposta formativa de origem.

Contando com 80 horas de formação, sendo 32 horas presenciais e 48 horas não presenciais, o planejamento da proposta formativa tem em seu cerne o compromisso com os diferentes componentes curriculares e a conexão destes com necessidades que extrapolam o contexto local. Por isso, as etapas e atividades terão como base os princípios hologramáticos, recursivos e dialógicos, acentuando possibilidades para o estímulo ao pensamento complexo. Nesse sentido, estimam pela valorização da solidariedade e do espírito de colaboração, priorizando o que Morin (2015) define como "prosa e poesia para o bem viver”. Prosa, nesse contexto, seria a rotina dos encontros, os horários, a discussão da base conceitual e as produções individuais e colaborativas. A poesia seria a alegria e o prazer dos encontros, as metáforas, a arte e a subjetividade. Reitera-se, dessa forma, a intenção da proposta formativa de "[...] propiciar a reflexão e a ação no sentido de resgatar a essência e a humanidade, por meio de perspectivas de resistência, emancipação e felicidade" (PETRAGLIA, 2008, p. 35).

Os encontros estão esquematizados previamente, mas preveem colóquios complexos (tecidos juntos), ecoformadores (conexões entre o eu, o outro e o meio ambiente) e transdisciplinares (vão além das bases conceituais e das disciplinas). A expectativa é de que, no decorrer da formação, sejam oportunizados momentos de valorização da convivência, de aprendizagens tecidas juntas, de compreensão das intencionalidades e de religação de iniciativas planejadas colaborativamente com o contexto local e global, motivados por uma perspectiva transdisciplinar e ecoformadora. Nesse processo, o foco estará naquilo que, mesmo que provisoriamente, seja possível.

A segunda pesquisa, desenvolvida por Marli Horn, terceira autora deste artigo, tem como objetivo avaliar os impactos do Programa de Formação-Ação em Escolas Criativas na prática pedagógica de docentes que atuam na Rede Municipal de Ensino de União da Vitória, Paraná, especialmente em relação ao trabalho colaborativo, à articulação do conteúdo com a realidade local e global e à transformação do entorno escolar. Os objetivos específicos também se aproximam da pesquisa anterior, contudo, por se constituir em uma intervenção (pesquisa-ação), o estudo também pretende sistematizar a percepção dos participantes sobre os impactos da formação continuada com ênfase transdisciplinar e ecoformadora na própria prática pedagógica e no contexto em que atuam.

Revista Devir Educação, Lavras, vol.2, n.4, p.232-250 jul./dez., 2020. 
A formação tem ocorrido no decorrer deste ano e, mesmo de forma remota, pela necessidade do isolamento social, os docentes discutiram conceitos fundamentais para o redimensionamento da prática pedagógica, elaboraram colaborativamente projetos de ensino e de aprendizagem para cada uma das escolas implicadas, ressignificando-os a partir da participação dos estudantes e das comunidades, que são estimuladas a participar do seu planejamento e desenvolvimento. Além disso, os resultados observados nas escolas vêm sendo discutidos nos encontros, valorizando, nesse processo, o protagonismo dos docentes que buscam transformar a prática pedagógica ao mesmo tempo que transformam sua forma de conceber a educação.

Destaca-se que todas as escolas se comprometeram em apresentar os projetos no Congresso de Educação e Saúde e no II Seminário de Ensino e Pesquisa com Intervenção, organizados pelo PPGEB em parceria com outras Instituições de Ensino Superior brasileiras e internacionais. Essa difusão constitui uma resposta ao questionamento de Nóvoa (2017, p. 1109) sobre "[...] como construir programas de formação de professores que nos permitam [...]" recuperar a ligação entre as escolas e os docentes "[...] enfraquecida nas últimas décadas, sem nunca deixar de valorizar a dimensão universitária, intelectual e investigativa?"

Da mesma forma, a segunda pesquisa procura atender o chamado de Behrens (2007, p. 445) quando a autora afirma que a formação de docentes "[...] requer processos de qualificação contínua e que abordem uma visão crítica, reflexiva e transformadora”. Para Moraes (2011), essas propostas formativas colaboram para que a problemática educacional seja pensada como um todo, evitando um discurso romântico que justifica a formação dos docentes com iniciativas fragmentadas.

\section{Considerações finais}

Superar práticas formativas atomizadas e descontextualizadas constitui tanto um desafio como uma possibilidade. Desafio por implicar uma realidade adversa e em acelerada transformação, e possibilidade porque, para Torre (2011), nos momentos adversos emergem muitas soluções criativas.

No caso da pesquisa com intervenção, existem muitas circunstâncias para transformar situações adversas em oportunidades de mudança da prática pedagógica na Educação Básica. Contudo, elas dependem do potencial que os mestrados profissionais oferecem para que os 
mestrandos investiguem as reais demandas do contexto de atuação e invistam em iniciativas que as atendam.

Nesse sentido, as perspectivas inter e transdisciplinar têm sido condições priorizadas no PPGEB. Da mesma forma, o viés ecoformador tem motivado os mestrandos a pautarem suas intervenções em iniciativas que valorizem o bem-estar individual e ambiental.

No caso específico das pesquisas com intervenção comprometidas com a formação docente, existem vários diferenciais que as caracterizam, entre eles: o fato de considerar as prioridades formativas dos docentes em formação; a organização de propostas com encontros articulados que possibilitam, além de reflexões epistemológicas, análises sobre o contexto de atuação; um planejamento colaborativo; o compromisso de propiciar espaços e momentos para que os docentes possam dialogar sobre suas iniciativas e conhecer as alternativas desenvolvidas pelos pares. Trata-se de um movimento recursivo fortalecido pela escuta, pela solidariedade e pela disponibilidade de compartilhar necessidades e valorizar o protagonismo docente.

Entre as opções, o PPGEB tem estimulado que esses momentos aconteçam no próprio campo de atuação dos mestrandos, ou seja, nas escolas de Educação Básica. Essa opção vai ao encontro da defesa feita por Nóvoa (2002) de que a formação precisa se dar no coletivo, pois é junto à transformação da escola que acontece a transformação do docente e, consequentemente, dos estudantes.

Além disso, o PPGEB tem promovido eventos internos, parte para um público restrito, parte para um público amplo. Mesmo remotamente, pela necessidade de isolamento social, os eventos deste ano têm possibilitado a interação entre os mestrandos, para que possam difundir suas iniciativas e conhecer as que têm sido dinamizadas em outros contextos, seja de outros programas de mestrado e doutorado no Brasil e no exterior, seja de profissionais da Educação Básica que são convidados para difundir seus avanços.

Com base nessas ações, o PPGEB fortalece a indissociabilidade entre ensino, pesquisa e extensão. Nesse processo, promove pesquisas com intervenção comprometidas com a formação docente e pautadas na transdisciplinaridade e na ecoformação.

\section{Referências}

ALMEIDA, Aline Lima da Rocha. Influência do programa de formação-ação em escolas criativas na transformação das práticas pedagógicas em uma escola do campo. 2018. 
141 p. Dissertação (Mestrado Profissional em Educação Básica) - Universidade Alto Vale do Rio do Peixe, Caçador, 2018.

ANDRÉ, Marli; PRINCEPE, Lisandra. O lugar da pesquisa no Mestrado Profissional em Educação. Educar em Revista, [s. l.], n. 63, p. 103-117, jan./mar. 2017. DOI: 10.1590/01044060.49805. Disponível em: https://www.scielo.br/pdf/er/n63/1984-0411-er-63-00103.pdf. Acesso em: 20 jun. 2019.

BEHRENS, Marilda. O paradigma da complexidade na formação e no desenvolvimento profissional de professores universitários. Educação, Porto Alegre, v. XXX, n. 63, set./dez. 2007. Disponível em: https://www.redalyc.org/articulo.oa?id=84806303 Acesso em: 5 mar. 2020.

FREIRE, Paulo. Pedagogia do oprimido. Rio de Janeiro: Paz e Terra, 1975.

GATTI, Bernardete Angelina. A formação inicial de professores para a educação básica: as licenciaturas. Revista USP, São Paulo, n. 100, p. 33-46, 18 fev. 2014. DOI: https://doi.org/10.11606/issn.2316-9036.v0i100p33-46. Disponível em: http://www.revistas.usp.br/revusp/article/view/76164. Acesso em: 18 dez. 2019.

GATTI, Bernardete Angelina. Formação de professores, complexidade e trabalho docente. Rev. Diálogo Educ., Curitiba, v. 17, n. 53, p. 721-737, 2017. DOI: https://doi.org/10.7213/1981-416X.17.052.AO01. Disponível em: https://periodicos.pucpr.br/index.php/dialogoeducacional/article/viewFile/8429/17739. Acesso em: 16 nov. 2019.

GATTI, Bernardete Angelina et al. Professores do Brasil: novos cenários de formação. Brasília: UNESCO, 2019.

IMBERNÓN, Francisco. Qualidade do ensino e formação do professorado: uma mudança necessária. Tradução de Silvana Cobucci Leite. São Paulo: Cortez, 2016.

MORAES, Maria Cândida. Ambientes de aprendizagem como expressão de convivência e transformação. In: MORAES, Maria Cândida; BATALLOSO NAVAS, Juan Miguel (org.). Complexidade e transdisciplinaridade em educação: teoria e prática docente. Rio de Janeiro: Wak Editora, 2010. p. 21-62.

MORAES, Maria Cândida. O paradigma educacional emergente: implicações na formação do professor e nas práticas pedagógicas. São Paulo: Cortez, 2011.

MORIN, Edgar. Ensinar a viver: manifesto para mudar a educação. Tradução de Edgard de Assis Carvalho e Mariza Perassi Bosco. Porto Alegre: Sulina, 2015.

MORIN, Edgar. Os sete saberes necessários à educação do futuro. Tradução: Catarina Eleonora F. da Silva e Jeanne Sawaya. 2. ed. São Paulo: Cortez; Brasília: UNESCO, 2011.

NICOLESCU, Basarab. Transdisciplinariedad: pasado, presente y futuro. In: ESPINOSA MARTINEZ, Ana Cecília; GALVANI, Pascal (org.). Transdisciplinariedad y formación universitária: teorias y prácticas emergentes. Puerto Vallarta: CEUArkos, 2014. p. 45-90.

NÓVOA, António. Firmar a posição como professor, afirmar a profissão docente. Cadernos de Pesquisa, v. 47, n. 166, p. 1106-1133 out./dez. 2017. Disponível em: http://www.scielo.br/pdf/cp/v47n166/1980-5314-cp-47-166-1106.pdf. Acesso em: 20 set. 2019.

NÓVOA, António. Formação de professores e trabalho pedagógico. Lisboa: Educa, 2002. 
NÓVOA, António (coord.). Os professores e a sua formação. Lisboa: Dom Quixote, 1992.

PETARNELlA, Leandro; SILVEIRA, Amélia. Programas de Mestrado Profissional em Educação e a intervenção na prática da ação. Dialogia, [s. l.], n. 22, p. 243-262, 2015. DOI: 10.5585/Dialogia.n22.5600. Disponível em: https://periodicos.uninove.br/dialogia/article/view/5600. Acesso em: 20 jun. 2020.

PETRAGLIA, Izabel. Educação complexa para uma nova política de civilização. Educar, Curitiba, v. 32, p. 29-41, 2008. Disponível em: https://www.scielo.br/pdf/er/n32/n32a04.pdf. Acesso em: 20 mar. 2020.

REBOLO, Flavinês; BUENO, Belmira Oliveira. O bem-estar docente: limites e possibilidades para a felicidade do professor no trabalho. Acta Scientiarum Education, Maringá, v. 36, n. 2, p. 323-331, jul./dez. 2014. DOI: https://doi.org/10.4025/actascieduc.v36i2.21222. Disponível em: http://periodicos.uem.br/ojs/index.php/ActaSciEduc/article/view/21222. Acesso em: 16 jul. 2020.

SÁ, Ricardo Antunes. Contribuições teórico-metodológicas do pensamento complexo para a construção de uma pedagogia complexa. In: SÁ, Ricardo Antunes; BEHRENS, Marilda Aparecida (org.). Teoria da complexidade: contribuições epistemológicas para uma pedagogia complexa. Curitiba: Appris, 2019. p. 17-64.

SILVA, Ana Tereza Reis. Ecoformação: reflexões para uma pedagogia ambiental, a partir de Rousseau, Morin e Pineau. Desenvolvimento e Meio Ambiente, Curitiba, n. 18, p. 95-104, jul./dez. 2008. DOI: http://dx.doi.org/10.5380/dma.v18i0.13428. Disponível em: https://revistas.ufpr.br/made/article/view/13428. Acesso em: 20 maio 2020.

TORRE, Saturnino de la. Adversidade e diversidade criadoras: desenvolvendo outra consciência. In: TORRE, Saturnino de la; ZWIEREWICZ, Marlene; FURLANETTO, Ecleide Cunico. Formação docente e pesquisa transdisciplinar: criar e inovar com outra consciência. Blumenau: Nova Letra, 2011. p. 47-74.

TORRE, Saturnino de la. O poder da palavra: significado e alcance da linguagem transdisciplinar e ecoformadora. In: TORRE, Saturnino de la; PUJOL, Maria Antonia; MORAES, Maria Cândida (org.). Transdisciplinaridade e Ecoformação: um novo olhar sobre a educação. São Paulo: TRIOM, 2008. p. 113-140.

UNIARP. Mestrado Profissional em Educação Básica. Caçador: UNIARP, 2018.

WERNECK, Guilherme Loureiro; CARVALHO, Marilia Sá. A pandemia de COVID-19 no Brasil: crônica de uma crise sanitária anunciada. Cadernos de Saúde Pública, Rio de Janeiro, v. 36, n. 5, p. 1-4, 2020. DOI: https://doi.org/10.1590/0102-311x00068820. Disponível em: https://www.arca.fiocruz.br/handle/icict/41242. Acesso em: 29 set. 2020.

ZIELINSKI, Helena Castilho. Indicadores de práticas transdisciplinares de leitura, produção e interpretação textual detectados no Programa de Formação-Ação em Escolas Criativas. 2019. 67 p. Dissertação (Mestrado Profissional em Educação Básica) Universidade Alto Vale do Rio do Peixe, Caçador, 2019.

ZWIEREWICZ, Marlene. Programa de Formação-Ação em Escolas Criativas: matizes da pedagogia ecossistêmica na formação de docentes da Educação Básica. In: DITTRICH, Maria Glória et al. (org.). Políticas Públicas na contemporaneidade: olhares cartográficos temáticos. Itajaí: Univali, 2017. p. 217-231. 


\section{OO DEVIR EDUCAÇÃO}

ISSN: 2526-849X

Recebido em: 30-09-2020

Aprovado em: 14-11-2020

Revista Devir Educação, Lavras, vol.2, n.4, p.232-250 jul./dez., 2020. 